\title{
Akarsu rehabilitasyonunun peyzaj kalitesi üzerindeki etkileri
}

\section{The effect of restoration process on riparian landscapes}

\author{
Nilgün GÜNEROĞLU
}

Karadeniz Teknik Üniversitesi, Orman Fakültesi, Peyzaj Mimarlığı Bölümü, Trabzon, Türkiye

\section{Eser Bilgisi / Article Info}

Araştırma makalesi / Research article DOI: 10.17474 /artvinofd. 270854

Sorumlu yazar / Corresponding author Nilgün GÜNEROĞLU

e-mail: nayhan@ktu.edu.tr

\section{Geliş tarihi / Received}

26.04.2016

Düzeltme tarihi / Received in revised form

29.11.2016

Elektronik erişim / Online available

30.11.2016

\section{Anahtar kelimeler:}

Akarsu kıyıları

Peyzaj rehabilitasyon

Peyzaj Kalitesi

Solaklı

Trabzon

\section{Keywords:}

\section{Riparian zones}

Landscape restoration

Landscape quality

Solaklı stream

Trabzon

\begin{abstract}
Özet
Akarsular ve kıyıları, hem kentsel hem de kırsal alanlarda canlılar için yaşam alanı oluşturmanın yanısıra, estetik, ekolojik ve rekreasyonel aktivitelere olanak sağlama gibi işlevlerle korunması ve rehabilite edilmesi gereken alanlardır. Bunun yanısıra, bu alanlar bulundukları çevrelerin estetik kalitesini arttırarak, kullanıılar için çekici rekreasyonel alanlar oluştururlar. Yeşil alanlarda olduğu gibi bu kıyılar da hızla artan nüfus ve plansız yapılaşma sebebiyle tahrip olmaktadır. Bu nedenlerle akarsu kıyılarının korunması ve yenilenmesi çevre dostu peyzaj tasarımları oluşturmak açısından öncelikli konular arasındadır. Çalışma, Trabzon Solaklı deresi kıyılarında yapılan rehabilitasyon çalışmalarının bu alanların peyzaj kalitesini arttırmada etkili olup olmadığını belirlemeyi hedeflemiştir. Bu amaçla çalışma alanının önceki ve sonraki durumunu yansıtan görüntüleri içeren anketler, alan kullanıcılarına sorgulanmıştır. Elde edilen 207 anket sonucuna göre alanın proje öncesi durumu ile proje sonrası durumunun peyzaj kaliteleri arasında olumlu yönde önemli farklılıklar olduğu gözlemlenmiştir. Yapılan rehabilitasyon çalışması akarsuyun ve kıyısının peyzaj değerini arttırmış ve kıyıya rekreasyonel kullanım potansiyeli kazandırmıştır. Sonuç olarak, akarsu rehabilitasyon çalışmalarının havza yönetim planları içerisine sokularak uygulanması gerektiği vurgulanmıştır.
\end{abstract}

\begin{abstract}
Riparian zones are unique landscapes that should be protected and restored by governing bodies as they offer habitats for various plants and animals. Moreover, these areas enhance the aesthetic quality and create recreationally attractive zones for the potential users. Urban sprawl and increasing populations are major threats for the riparian ecosystems as it is experienced in the case of deforestation. Therefore, protecting and restoring riparian areas is an issue of high priority for creating eco-friendly recreational facilities. This study aims at investigation of the Trabzon-Solaklı streamside restoration project in terms of its contribution to overall landscape quality of the area. For this purpose, pre and post project images of the area were shown to the users to receive their evaluation and scoring of the related landscape attributes by applying a questionnaire. According to 207 respondents, the overall landscape quality of the Solaklı stream was greatly and positively enhanced. Landscape value and recreational potential of the region was also increased after the streamside restoration. It is concluded that streamside restoration projects should be applied and embedded in to river basin management plans.
\end{abstract}

\section{GíRiş}

Suyun kara ile birleştiği yer olan kıyılar geçmişten günümüze birçok medeniyet için en önemli yaşam alanları olmuşlardır. Doğal bir kaynak olan kıyılar sadece bir çizgiden ibaret olmayıp birçok değişik bitki ve hayvan türüne uygun habitatlar sağlayan alanlardan meydana gelirler (Kilıçaslan 2006; Gülez vd. 2007). Dünya nüfusunun üçte ikisi kıyısal alanlarda bulunmakta ve bu alanlardaki nüfus iç bölgelerdekinden oldukça fazla artmaktadır (Uzun ve Çelik 2014; Guneroglu 2015; Guneroglu vd. 2016).

Kıyı kavramı, sadece deniz kıyıları değil göl, baraj ve akarsu kıyılarını da içine alan bir tanımdır. Özellikle dünyadaki karaları bir ağ gibi örtmüş olan akarsular ve kıyıları, büyük medeniyetlerin kurulduğu ve geliştiği alanlardır. Bu alanlar ilk bakışta içme suyu temini, temizlik ve sulama gibi amaçlar ile tercih edilse de tarım, hayvan yetiştirme, maden çıkarma, enerji üretimi, ulaşım, rekreasyon, turizm ve estetik amaçlı birçok kullanıma olanak sağlamaktadır (Guneroglu vd. 2014 ).

Dünyada ve Türkiye'de zaman içinde farklı amaçlarla kullanılan akarsu kıyıları, kentleşme, kaynak kullanımı, ham madde ve enerji arayışı gibi amaçlarla zarar görmüş ve şekil değiştirmiştir. Bunun sonucunda can ve mal kayıplarına neden olmuş, her hangi bir amaca yönelik kullanılmayan peyzajlar haline gelerek peyzaj kalitelerini kaybetmişlerdir. Son yıllarda yapılan çalışmalarda bu 
alanlara gerekli önemin verilmediği ve kullanıma kazandırılmaları gerekliliği üzerinde durulmaktadır (Önen 2007). Ülkemizde de bu şekilde gerçekleştirilen birçok rehebilitasyon çalışması bulunmaktadır. Özellikle kentsel alanlarda gerçekleştirilen çalışmalarda akarsu kıyılarının görsel peyzaj kalitesinin arttırılarak yeşil alan ve rekreasyonel olanaklar sağlaması açısından kentlere kazandırıldığı gözlemlenmiştir (Özgüner vd. 2012; Sağlık vd. 2012).

"Görsel peyzaj kalitesi, gözlemcinin algısal ve duygusal psikolojik süreçleri ile etkileşim içinde olan belli (görünür) peyzaj özelliklerinin ortak bir ürünüdür. Çevrenin insan üzerindeki davranışa dönüşen bu etkisinin nasıl algılandığı nasıl yorumlandığı ve nasıl değerlendirildiği, görsel algılama süreci sonucunda oluşan "görsel peyzaj kalitesi" olarak tanımlamaktadır. Görsel peyzaj kalitesi "bir peyzajın göreceli olarak estetik kusursuzluğu" olarak da tanımlanabilir ve gözlemcinin beğenisi aracılığı ile ölçülebilir." (Daniel 2001; Kalın 2004; De La Fuente vd. 2006; Özgeriş ve Karahan 2015; Gültürk ve Şişman 2015). Bu ölçümlerden en önemlilerinden ve metodolojik olarak araştırılan görsel kalite değerlendirmesidir. Görsel kalite değerlendirilmesi peyzaj görüntülerinin fotoğrafik sunumuna dayalı katılımcı değerlendirilmeleriyle gerçekleştirilir (Daniel 2001; Dramstad vd. 2006; Bulut ve Yılmaz 2008).

Su, peyzajda en önemli görsel çekicilik kaynağı ve rekereasyonel aktiviteler için ilk sırada tercih edilen bir öğedir. Peyzajda suyun estetik bir eleman olarak önemi Mezopotamya ve Mısır bahçelerine kadar dayanır. Kendine ait bir formu olmayıp bulunduğu alana göre şekillenen su, ister durgun, ister hareketli olsun birçok peyzaja şekil veren ana elemanlardan biridir (Burmil vd. 1999). Peyzajda suyun estetik ve görsel özelliklerini karakterize eden, su ile birlikte vejetasyon örtüsü, doku, renk ve form açısından doğayla uyumlu mimari öğelere sahip alanların görsel kaliteyi yükselttiğini ve kullanıcılar tarafından rekrasyonel amaçlar için daha çok tercih edildiğini ortaya koyan çalışmalar bulunmaktadır (Yamashita 2002; Özhancı ve Yılmaz 2011; Özgeriş ve Karahan 2015).
Doğu Karadeniz bölgesi birçok su kaynağına (deniz, göl, akarsu, baraj gölü) ve bu kaynaklara bağlı olarak önemli peyzajlara sahiptir. Arazi yapısının çok engebeli ve yağışların yoğun olmasından dolayı bölgedeki akarsuların su oranı fazla ve bitki örtüsü oldukça zengindir (Acar 2001; Terzioğlu vd. 2007). Bölgedeki akarsular ve kıyıları sahip oldukları yeşil dokularla etkili peyzajlara ve rekreasyonel potansiyele sahip olmalarına rağmen yapılaşma, sanayi, tarım ve enerji kaynağı olarak kullanımları peyzaj kalitelerine zarar vermektedir. Bu alanlardan özellikle alt ve üst yapı eksiklikleri nedeniyle yeterince faydalanılamamaktadır.

Bu çalışmada Trabzon'un Of ilçesinde bulunan Solaklı deresi ve kıyılarında gerçekleştirilen rehabilitasyon çalışmalarının alanın önceki ve sonraki durumu göz önünde bulundurularak peyzaj kalitesine olan etkilerinin belirlenmesi hedeflenmiştir. Peyzaj kalitesine bağlı olarak rekreasyonel kullanım durumundaki değişimler incelenmiştir. Rehabilitasyon çalışmalarının havza yönetimi planları içerisine etkin bir şekilde sokulması ve bunun da uygulama projeleri ile ortaya konması gerekliliği üzerinde durulmuştur.

\section{MATERYAL VE YÖNTEM}

\section{Çalışma Alanı}

Trabzon, Türkiye coğrafyasında Karadeniz Bölgesi'nin Doğu Karadeniz bölümünde yer alan Karadeniz'e kıyısı olan bir ildir. Sarp ve dağlık bir araziye sahip olan Trabzon'da küçüklü büyüklü hızlı akan çok sayıda dere bulunmaktadır. Fol, Söğütlü, Değirmendere, Yomra, Yanbolu, Karadere, Küçükdere, Sürmene, Baltacı, Solaklı, İyidere, Büyükdere, Taşlıdere, Hemşin ve Fırtına bunların en büyüklerindendir (Guneroglu 2010). Bu büyük akarsulardan biri olan Solaklı deresi, Trabzon'un Of, Dernekpazarı ve Çaykara ilçelerinden geçmektedir (Şekil 1). Solaklı deresi anakolu yaklaşık $56 \mathrm{~km}$ uzunluğunda (Aksungur vd. 2007) olup, kaynağı güneyde Horos Soğanlı ve Haldizen Dağları'nda başlar ve en son Trabzon'un Of ilçesinden Karadenize dökülür. 


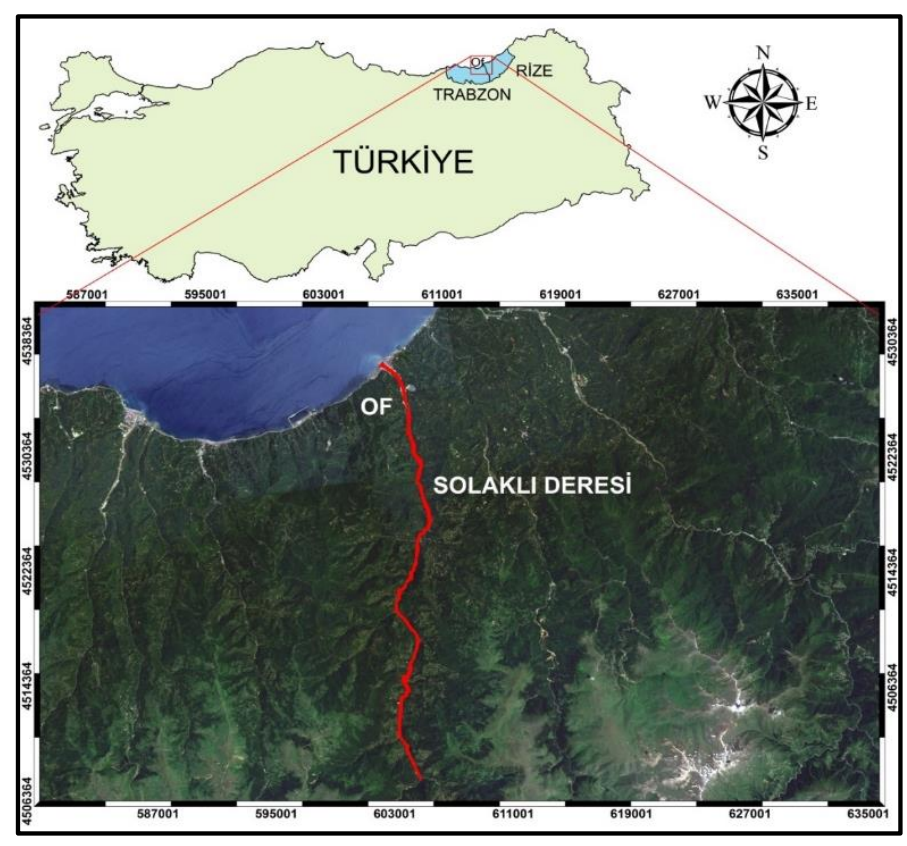

Şekil 1. Çalışma alanı konumu

Çalışmanın ana materyalini Solaklı deresi Of ve Çaykara ilçeleri arasındaki yaklaşık 20 kilometre uzunluğundaki güzergahta uygulanan "Solaklı Vadisi İyileştirme Projesi" kapsamında tamamlanan göletler ve park alanlarından oluşturmaktadır (Şekil 2). Bu proje, Orman ve Su İşleri Bakanlığı'na bağlı Devlet Su İşleri Genel Müdürlüğü ile Orman Genel Müdürlüğü ve Karadeniz Teknik Üniversitesi Orman Fakültesi ile birlikte yürütülmüştür. Proje ile birlikte taşkın koruma, rehabilitasyon ve çevre düzenlemesi çalışmalarıyla havzanın rehabilite edilmesi, hem yöre halkına dinlenme ve mesire alanı kazandırılması hem de korunması gereken bitki türlerinin korunması düşünülmüştür (URL_1). Ayrıca havzanın tabi güzellikleri, tarihi eserleri ve ekosisteminin ortaya çıkarılarak korunması ve yörede turizm gelirlerinin arttırılması planlanmıştır (URL_2).

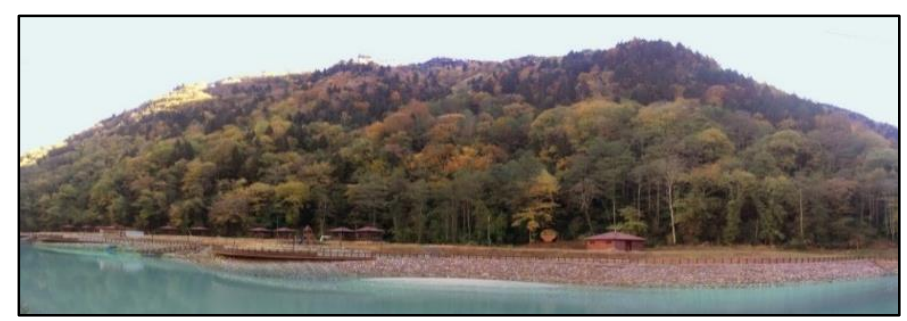

Şekil 2. Çalışma alanı

\section{Peyzaj Kalite Analizi}

Akarsu kıyılarında gerçekleştirilen rehabilitasyon çalışmalarının, uygulama alanlarının önceki ve sonraki yapıları göz önünde bulundurarak peyzaj kalitesi üzerindeki etkileri araştırımıştır. Bu amaçla çalışma 5 aşamada gerçekleştirilmiştir (Şekil 3).

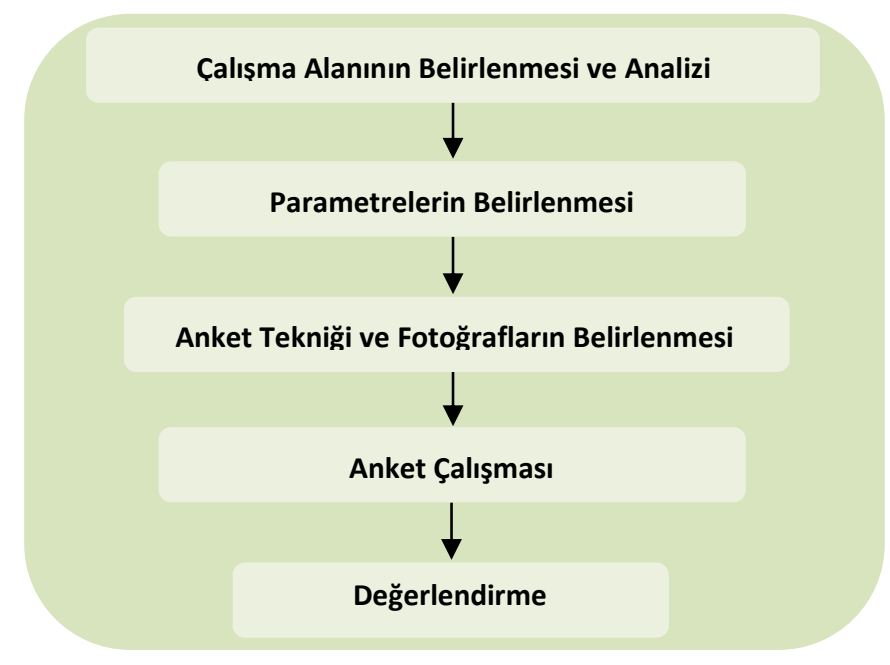

Şekil 3. Çalışma aşamaları

Trabzon şehrinde birçok akarsu yanlış kullanımlardan ötürü doğal yapısını kaybederek kullanılmayan niteliksiz peyzajlar sunmaktadır. Çalışma alanı olarak seçilen alan akarsu kıyıları bölgede yapılan hidroelektrik üretim çalışmaları sonrasında yeni bir planlama ile rehabilite edilerek dönüşüme uğramıştır. Bu nedenle çalışma alanı olarak seçilmiş ve çalışma konusu ve alan ile ilgili literatür araştırması yapılmıştır.

Çalışma ile ilgili olarak yapılan anketler üç bölümden oluşmaktadır. İlk bölüm katılımcı profilini, ikinci bölümde alanın rekreasyonel olanaklarına bağlı olarak tercih edilme durumunu ve son bölüm ise peyzaj kalitesini belirlenemeye yönelik hazırlanmıştır. Çalışmada peyzaj kalitesini değerlendirmek içi kullanılan parametreler, literatür çalışmaları sonucunda elde edilmiş olup çizgi, renk, doku, form, süreklilik, birlik, algılanabilirlik, uyum, çeşitlilik, karmaşıklık, güzel, özgün, etkileyici, bakımlı, doğal, rahatlatıcı, beğeni, rekreatif, ulaşılabilir, hatırlanabilir, tanıdık, güvenli, koruma, geliştirme ve yenileme şeklinde belirlenmiştir (Hunziker ve Kienast, 1999; Clay ve Smidt, 2004; Müderrisoğlu ve Eroğlu, 2006; Bulut ve Yılmaz, 2008; Acar ve Sakıcı, 2008; Acar ve Güneroğlu, 2009). Akarsu kıyılarının peyzaj kalitesinin 
belirlenmesinde "Likert Tutum Skalası" kullanılmıştır. Belirlenen 25 parametre katılımcıların anlayabileceği 25 soruya dönüştürülerek katılımcılara sorgulanmıştır. Katılımcıların bu kavramlara katılma dereceleri 5'li olup 'Kesinlikle katıliyorum', 'Katıliyorum', 'Fikrim yok', 'Katılmıyorum', 'Kesinlikle katılmıyorum' değerlendirmelerini içerir. Anketlerde alanın önceki ve sonraki durumunu temsil eden fotoğraflar, çeşitli kaynaklardan ve alan çalışmasında gerçekleştirilen fotoğraflama çalışmaları ile elde edilmiştir (Şekil 4). Anket soruları ve alana ait fotoğrafların elde edilmesiyle oluşturulan anketler 207 katılımcı ile birebir yapılmıştır. Anket formunun nasıl değerlendirileceğinin anlatılarak başlandığı görüşmeler toplam 10-15 dakika sürmüştür.

Alanın önceki ve sonraki durumunun peyzaj kalitesinin belirlenmesi ve iki dönem arasındaki farklılıkların ortaya

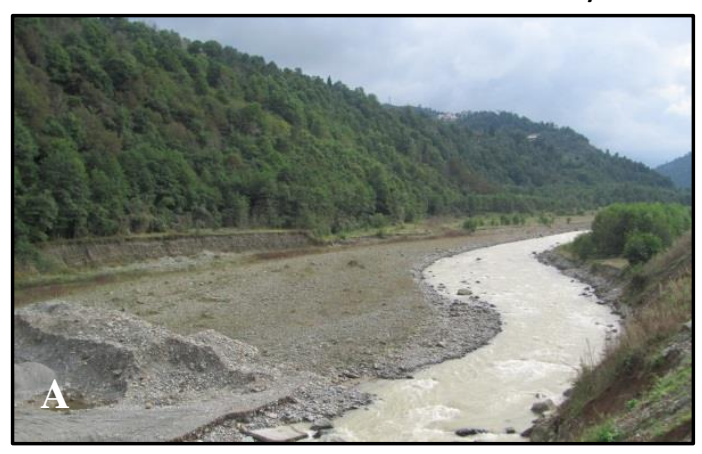

konması amacı ile yapılan anket sonuçlarından peyzaj kalite parametrelerinin tanımlayıcı ve çıkarımsal istatistikleri belirlenmiştir. Tanımlayıcı istatistiklerin her bir parametre ortalamaları üzerinden varyans analizleri yapılmıştır. Yapılan varyans analizi (ANOVA) testlerinde peyzaj kalite parametrelerinin değişimlerinin istatistiki olarak farklı olup olmadıkları ve gruplar oluşturup oluşturmadıkları belirlenmiştir. Parametrelerin birbirlerine olan etkilerini belirlemek için korelasyon analizi uygulanmıştır. Çalışma faktör analizi kullanılarak peyzaj kalitesini ortaya çıkarmada en etkin faktörleri belirlemek şeklinde devam etmiştir. İstatistiksel analizlerin tümü SPSS 11.5 ortamında gerçekleştirilmiştir. Böylece alanın önceki ve sonraki durumu için katılımcıların her bir parametreye olan katılım düzeyi ve tercih edilebilirliğini belirleyen kaliteler ölçülmüştür.

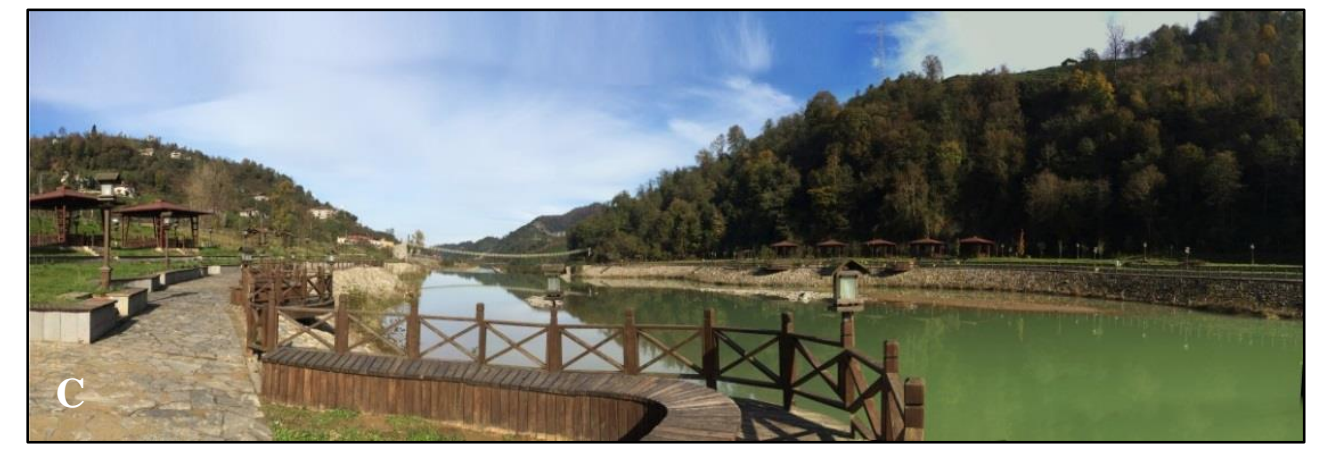

Şekil 4. A, B alanın önceki durumunu ve $C$ sonraki durumunu gösteren fotoğraflar

\section{BULGULAR}

Akarsu kıyı rehabilitasyonunun peyzaj kalitesi üzerine etkisinin araştırılığı çalışmada Solaklı Vadisi iyileştirme projesi kapsamında solaklı akarsuyu kıyılarında yapılan çevre düzenlemelerinin alanın önceki ve sonraki durumu düşünülerek peyzaj kalitesine olan etkileri belirlenmiştir. Anket çalışmalarıyla kullanıcı memnuniyeti belirlenerek bu etkiler irdelenmiştir.

\section{Katılımcı Profili}

Katılımcıların sosyo-ekonomik durumuna ait bilgiler Tablo 2 'de verilmiştir. Katılımcılıların her yaş grubundan ve eğitim düzeylerinin çoğunlukla lise, üniversite ve lisansüstü olduğu görülmektedir. Katılımcıların \%56'sını bayanlar geri kalan \%44'lük kısmı ise baylar oluştururken bunların \%52'si evli \%48'i ise bekardır. 
Tablo 2. Katılımcıların sosyo demografik durumu

\begin{tabular}{|c|c|c|c|c|c|}
\hline Katılımcı Özellikleri & Sayı & Yüzde (\%) & Katılımcı Özellikleri & Sayı & Yüzde (\%) \\
\hline Medeni durum & & & Cinsiyet & & \\
\hline Evli & 107 & 52 & Bay & 92 & 44 \\
\hline Bekar & 100 & 48 & Bayan & 115 & 56 \\
\hline Eğitim & & & Yaş & & \\
\hline Tahsilsiz & - & & $15-20$ & 8 & 4 \\
\hline İlkokul & 7 & 3 & $20-25$ & 55 & 26 \\
\hline Ortaokul & 10 & 5 & $25-30$ & 21 & 10 \\
\hline Lise & 47 & 23 & $30-35$ & 47 & 23 \\
\hline Üniversite & 93 & 45 & $35-45$ & 41 & 20 \\
\hline Lisansüstü & 50 & 24 & 45 ve üzeri & 35 & 17 \\
\hline Meslek & & & Aylık gelir & & \\
\hline İşsiz & 8 & 4 & Yok & 56 & 27 \\
\hline Öğrenci & 43 & 21 & $500-1000$ & 11 & 5 \\
\hline Memur & 39 & 19 & $1000-2000$ & 20 & 10 \\
\hline İşçi & 16 & 7 & $2000-3000$ & 39 & 19 \\
\hline Ev hanımı & 13 & 6 & 3000 ve üstü & 81 & 39 \\
\hline Emekli & 10 & 5 & & & \\
\hline Esnaf & 8 & 4 & & & \\
\hline Diğer & 70 & 34 & & & \\
\hline
\end{tabular}

\section{Rekreasyonel Kullanım Durumu}

Yapılan anketler sonucunda katılımcıların projenin önceki durumunu herhangi bir kullanım amacı ile tercih etmedikleri hatta alanın farkındalığının olmadığı ortaya çıkmıştır (Şekil 5). Gerçekleştirilen proje ile birlikte çalışma alanının yeni bir yüz kazandığı ve rekreasyonel olanak açısından önem kazandığı belirlenmiştir.

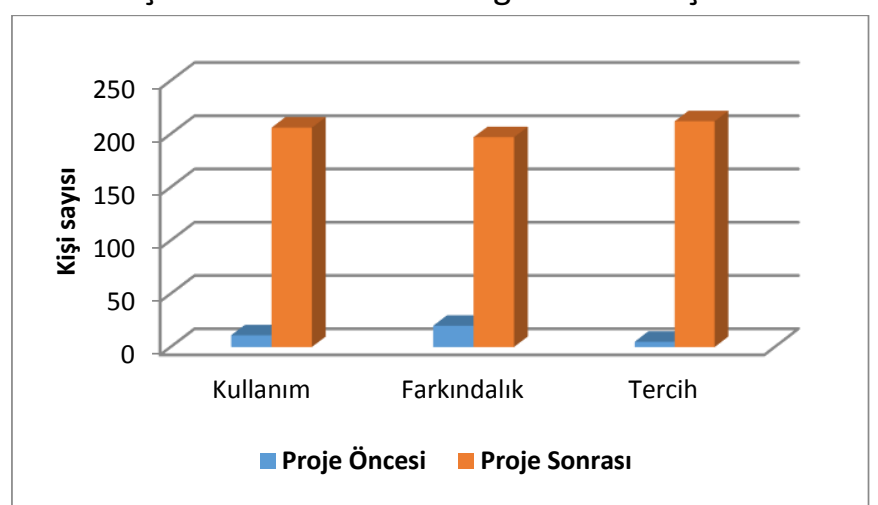

Şekil 5. Alanın önceki ve sonraki durumunun kullanım sıklığı, farkındalık ve tercih edilme oranı

Alanın proje sonrası kullanım durumunun daha çok tercih edildiğini belirledikten sonra hangi faktörlerin alanın tercih edilmesinde etkili olduğu incelenmiştir (Şekil 6). Alanın su kenarında, yeşil alan içinde bulunuşu, oturma alanlarının varlığı, manzara güzelliği, güvenli, bakımlı ve ulaşılabilir oluşu nedeniyle piknik yapma, dinlenme ve fotoğraf çekme gibi rekreatif etkinliklere olanak sağladığı belirlenmiştir.

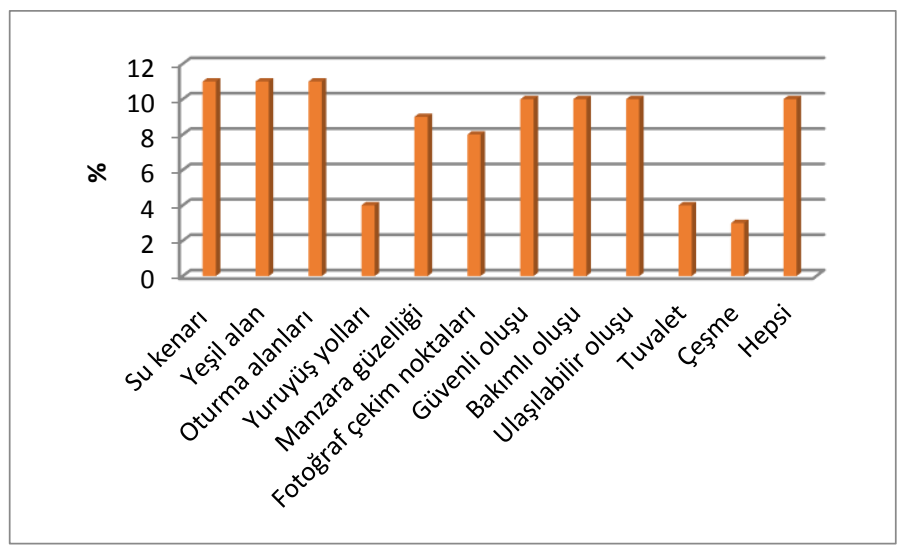

Şekil 6. Tercih edilmede etkin faktörler

\section{Peyzaj Kalite Analizi}

Tüm değişkenlerin kendi aralarındaki ilişkiyi ortaya koymak için korelasyon analizi yapılmıştır. \%99 önem düzeyinde elde edilen Pearson korelasyon katsayıları hesaplanmıştır. Buna göre, bakım ve rekreatif arasında $r=0.935$ ve $(p<0.01)$ en yüksek korelasyon elde edilmiştir. Benzer şekilde güzel-etkileyici arasında $r=0.907$, $(p<0.01)$ ve rekreatif-hatırlanabilir arasında $r=0.930, \quad(p<0.01)$ tespit edilmiştir. Bunları sırası ile etkileyici-bakım, güvenlibakım ve beğeni-bakım arasında anlamlı ( $r \quad 20,8)$ sayılabilecek değerler saptanmıştır. Bunların dışında aşağıda Tablo 3’ de elde edilen tüm değerler verilmiştir. 


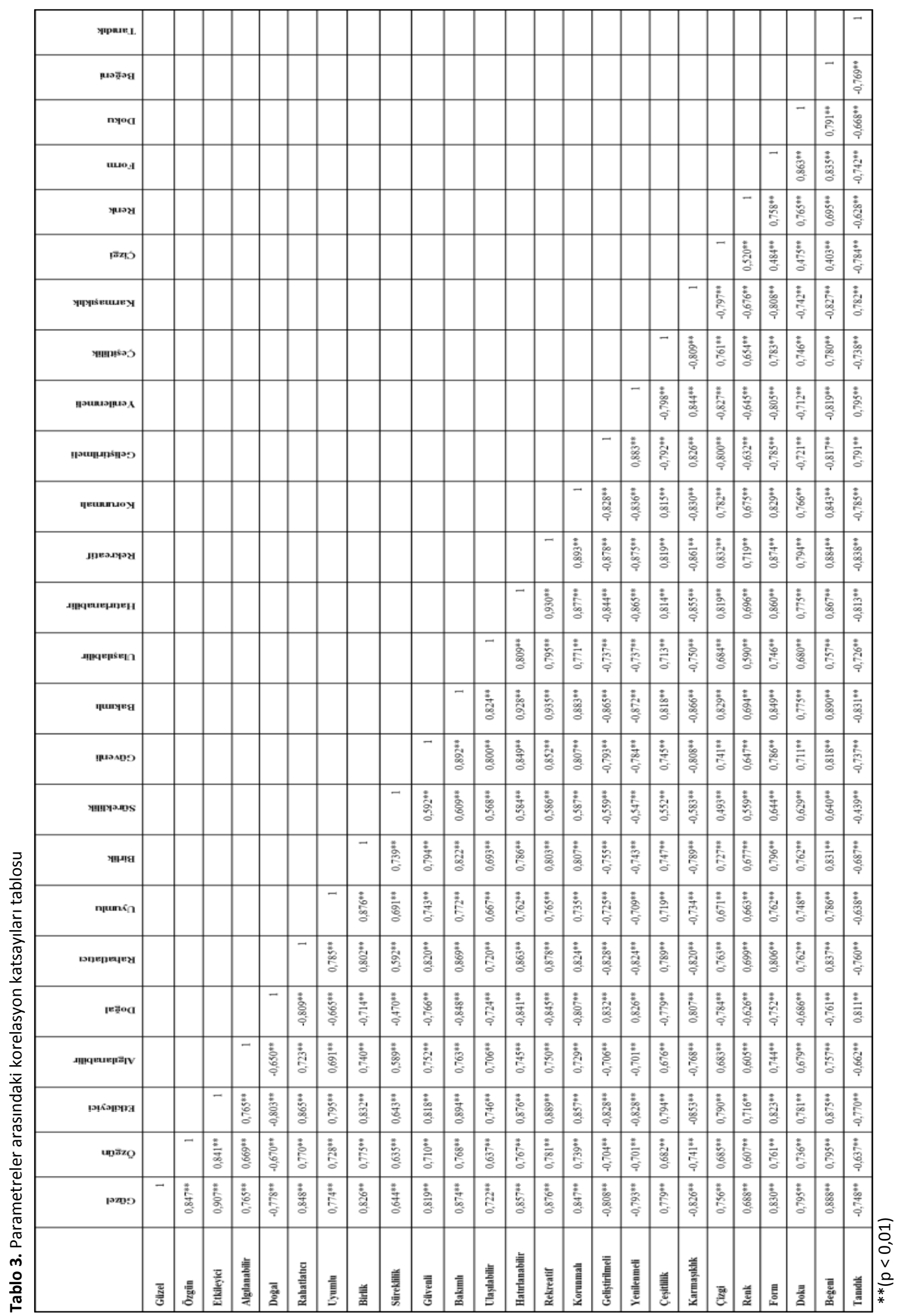


Çalışma alanının eski ve yeni durumunun peyzaj kalitesini ortaya koyan parametreler ANOVA testi sonucuna göre irdelendiğinde, alanın yeni durumu; "Güzel" (4.53), "Özgün" (4.06), "Etkileyici" (4.41), "Algılanabilir" (4.55), "Rahatlatıcı" (4.46), "Uyumlu" (4.44), "Birlik" (4.55), "Süreklilik" (4.45), "Güvenli" (4.40), "Bakımlı" (4.71), "Ulaşılabilir" (4.58), "Hatırlanabilir" (4.67), "Rekreatif"
(4.83), "Korunmalı" (4.60), "Çeşitlilik" (4.26), "Çizgi" (4.33), "Renk" (4.20), "Form" (4.54), "Doku" (4.31), "Beğeni" (4.63) parametrelerinde yüksek skorlar almıştır $(p<0.01)$. Bunun yanında alanın eski durumu ise "Doğal" (4.43), "Geliştirilmeli" (4.73), "Yenilenmeli" (4.72), "Karmaşıklık" (4.17), "Tanıdık" (4.30) parametrelerinde yüksek skorlar almıştır ( $p<0.01$ ) (Tablo 4).

Tablo 4. Peyzaj kalite parametreleri için ANOVA tablosu

\begin{tabular}{|c|c|c|c|c|c|c|c|c|}
\hline & & $\mathrm{N}$ & Mean & Std. Deviation & Lower Bound & Upper Bound & $\mathrm{F}$ & Sig. \\
\hline & 1 & 207 & 1.77 & 0.90 & 1.64 & 1.89 & 1352.7 & 0.000 \\
\hline \multirow[t]{3}{*}{ Güzel } & 2 & 207 & 4.55 & 0.61 & 4.47 & 4.63 & & \\
\hline & Total & 414 & 3.16 & 1.59 & 3.01 & 3.31 & & \\
\hline & 1 & 207 & 1.82 & 0.97 & 1.68 & 1.95 & 573.5 & 0.000 \\
\hline \multirow[t]{3}{*}{ Özgün } & 2 & 207 & 4.06 & 0.94 & 3.93 & 4.19 & & \\
\hline & Total & 414 & 2.94 & 1.47 & 2.80 & 3.08 & & \\
\hline & 1 & 207 & 1.67 & 0.69 & 1.57 & 1.76 & 1573.1 & 0.000 \\
\hline \multirow[t]{3}{*}{ Etkileyici } & 2 & 207 & 4.41 & 0.72 & 4.31 & 4.51 & & \\
\hline & Total & 414 & 3.04 & 1.54 & 2.89 & 3.19 & & \\
\hline & 1 & 207 & 2.39 & 1.25 & 2.22 & 2.56 & 511.8 & 0.000 \\
\hline \multirow[t]{3}{*}{ Algılanabilir } & 2 & 207 & 4.55 & 0.56 & 4.47 & 4.63 & & \\
\hline & Total & 414 & 3.47 & 1.45 & 3.33 & 3.61 & & \\
\hline & 1 & 207 & 4.43 & 0.61 & 4.34 & 4.51 & 1633.9 & 0.000 \\
\hline \multirow[t]{3}{*}{ Doğal } & 2 & 207 & 1.84 & 0.69 & 1.75 & 1.93 & & \\
\hline & Total & 414 & 3.13 & 1.45 & 2.99 & 3.27 & & \\
\hline & 1 & 207 & 1.83 & 0.80 & 1.72 & 1.94 & 1399.2 & 0.000 \\
\hline \multirow[t]{3}{*}{ Rahatlatıcı } & 2 & 207 & 4.46 & 0.61 & 4.37 & 4.54 & & \\
\hline & Total & 414 & 3.14 & 1.49 & 3.00 & 3.29 & & \\
\hline & 1 & 207 & 2.29 & 1.05 & 2.15 & 2.44 & 576.9 & 0.000 \\
\hline \multirow[t]{3}{*}{ Uyumlu } & 2 & 207 & 4.44 & 0.73 & 4.34 & 4.54 & & \\
\hline & Total & 414 & 3.37 & 1.41 & 3.23 & 3.50 & & \\
\hline & 1 & 207 & 2.17 & 1.04 & 2.03 & 2.32 & 784.8 & 0.000 \\
\hline \multirow[t]{3}{*}{ Birlik } & 2 & 207 & 4.55 & 0.64 & 4.46 & 4.64 & & \\
\hline & Total & 414 & 3.36 & 1.47 & 3.22 & 3.50 & & \\
\hline & 1 & 207 & 2.93 & 1.28 & 2.76 & 3.11 & 221.9 & 0.000 \\
\hline \multirow[t]{3}{*}{ Süreklilik } & 2 & 207 & 4.45 & 0.72 & 4.35 & 4.55 & & \\
\hline & Total & 414 & 3.69 & 1.28 & 3.57 & 3.81 & & \\
\hline & 1 & 207 & 1.77 & 0.90 & 1.64 & 1.89 & 1042.9 & 0.000 \\
\hline \multirow[t]{3}{*}{ Güvenli } & 2 & 207 & 4.40 & 0.75 & 4.29 & 4.50 & & \\
\hline & Total & 414 & 3.08 & 1.55 & 2.93 & 3.23 & & \\
\hline & 1 & 207 & 1.38 & 0.66 & 1.29 & 1.47 & 3200.0 & 0.000 \\
\hline \multirow[t]{3}{*}{ Bakımlı } & 2 & 207 & 4.71 & 0.53 & 4.63 & 4.78 & & \\
\hline & Total & 414 & 3.04 & 1.77 & 2.87 & 3.21 & & \\
\hline & 1 & 207 & 2.23 & 1.11 & 2.08 & 2.38 & 722.3 & 0.000 \\
\hline \multirow[t]{3}{*}{ Ulaşılabilir } & 2 & 207 & 4.58 & 0.60 & 4.50 & 4.66 & & \\
\hline & Total & 414 & 3.40 & 1.48 & 3.26 & 3.55 & & \\
\hline & 1 & 207 & 1.63 & 0.69 & 1.53 & 1.72 & 2584.2 & 0.000 \\
\hline \multirow[t]{3}{*}{ Hatırlanabilir } & 2 & 207 & 4.67 & 0.51 & 4.60 & 4.74 & & \\
\hline & Total & 414 & 3.15 & 1.64 & 2.99 & 3.31 & & \\
\hline & 1 & 207 & 1.44 & 0.67 & 1.35 & 1.54 & 3969.3 & 0.000 \\
\hline \multirow[t]{2}{*}{ Rekreatif } & 2 & 207 & 4.83 & 0.38 & 4.77 & 4.88 & & \\
\hline & Total & 414 & 3.14 & 1.78 & 2.96 & 3.31 & & \\
\hline
\end{tabular}




\begin{tabular}{|c|c|c|c|c|c|c|c|c|}
\hline & & $\mathrm{N}$ & Mean & Std. Deviation & Lower Bound & Upper Bound & $\mathrm{F}$ & Sig. \\
\hline & 1 & 207 & 1.65 & 0.79 & 1.54 & 1.76 & 1827.1 & 0.000 \\
\hline \multirow[t]{3}{*}{ Korunmalı } & 2 & 207 & 4.60 & 0.60 & 4.52 & 4.68 & & \\
\hline & Total & 414 & 3.13 & 1.63 & 2.97 & 3.28 & & \\
\hline & 1 & 207 & 4.73 & 0.52 & 4.66 & 4.80 & 2047.6 & 0.000 \\
\hline \multirow[t]{3}{*}{ Geliştirilmeli } & 2 & 207 & 1.87 & 0.75 & 1.77 & 1.97 & & \\
\hline & Total & 414 & 3.30 & 1.57 & 3.15 & 3.45 & & \\
\hline & 1 & 207 & 4.72 & 0.51 & 4.65 & 4.79 & 1921.7 & 0.000 \\
\hline \multirow[t]{3}{*}{ Yenilenmeli } & 2 & 207 & 1.90 & 0.77 & 1.77 & 2.00 & & \\
\hline & Total & 414 & 3.31 & 1.56 & 3.16 & 3.46 & & \\
\hline & 1 & 207 & 1.89 & 0.84 & 1.78 & 2.01 & 997.4 & 0.000 \\
\hline \multirow[t]{3}{*}{ Çeşitlilik } & 2 & 207 & 4.26 & 0.68 & 4.17 & 4.35 & & \\
\hline & Total & 414 & 3.08 & 1.41 & 2.94 & 3.21 & & \\
\hline & 1 & 207 & 4.17 & 0.667 & 4.08 & 4.27 & 1482.8 & 0.000 \\
\hline \multirow[t]{3}{*}{ Karmaşıklık } & 2 & 207 & 1.68 & 0.65 & 1.59 & 1.77 & & \\
\hline & Total & 414 & 2.93 & 1.41 & 2.79 & 3.06 & & \\
\hline & 1 & 207 & 1.71 & 0.81 & 1.60 & 1.82 & 1258.6 & 0.000 \\
\hline \multirow[t]{3}{*}{ Çizgi } & 2 & 207 & 4.33 & 0.69 & 4.23 & 4.42 & & \\
\hline & Total & 414 & 3.02 & 1.51 & 2.87 & 3.17 & & \\
\hline & 1 & 207 & 2.30 & 1.08 & 2.15 & 2.45 & 401.4 & 0.000 \\
\hline \multirow[t]{3}{*}{ Renk } & 2 & 207 & 4.20 & 0.84 & 4.09 & 4.32 & & \\
\hline & Total & 414 & 3.25 & 1.36 & 3.12 & 3.38 & & \\
\hline & 1 & 207 & 1.95 & 0.90 & 1.83 & 2.08 & 1139.4 & 0.000 \\
\hline \multirow[t]{3}{*}{ Form } & 2 & 207 & 4.54 & 0.64 & 4.45 & 4.63 & & \\
\hline & Total & 414 & 3.25 & 1.51 & 3.10 & 3.39 & & \\
\hline & 1 & 207 & 2.14 & 1.01 & 2.00 & 2.27 & 617.4 & 0.000 \\
\hline \multirow[t]{3}{*}{ Doku } & 2 & 207 & 4.31 & 0.75 & 4.21 & 4.41 & & \\
\hline & Total & 414 & 3.22 & 1.41 & 3.09 & 3.36 & & \\
\hline & 1 & 207 & 1.70 & 0.90 & 1.57 & 1.81 & 1460.3 & 0.000 \\
\hline \multirow[t]{3}{*}{ Beğeni } & 2 & 207 & 4.63 & 0.64 & 4.55 & 4.72 & & \\
\hline & Total & 414 & 3.16 & 1.67 & 3.00 & 3.33 & & \\
\hline & 1 & 207 & 4.30 & 0.67 & 4.21 & 4.40 & 1293.1 & 0.000 \\
\hline \multirow[t]{2}{*}{ Tanıdık } & 2 & 207 & 1.80 & 0.75 & 1.69 & 1.90 & & \\
\hline & Total & 414 & 3.05 & 1.44 & 2.91 & 3.19 & & \\
\hline
\end{tabular}

Bir sonraki aşamada ise temel bileşenler analizi ile peyzaj kalitesini ortaya çıkmasında en etkili ilk 6 bileşen bulunmuş ve faktör analizi gerçekleştirilmiştir. Faktör analizi sonuçlarına ait faktör yükü ve ortak varyans değerini belirten tablo aşağıda sunulmuştur (Tablo 5). Buna göre toplam varyansın \%31.2'sini açıklayan 1. faktörün ortaya çıkmasında "Güzel, Özgün, Etkileyici, Rahatlatıcı, Uyumlu, Birlik, Süreklilik" parametreleri etkili olurken, varyansın \%8.1'inden sorumlu olan 2. faktörün ortaya çıkmasında "Algılanabilir, Güvenli, Bakımlı, Ulaşılabilir, Hatırlanabilir, Rekreatif, Çeşitlilik" parametreleri etkili olmuştur. 3. faktör toplam varyansın \%5.8'lik kısmını açıklayan "Koruma, Renk, Form, Doku, Beğeni" parametreleri, 4. faktör ise toplam varyansın \%5.4'lük kısmını açıklayan "Doğal, Tanıdık, Karmaşıklık" parametreleri, 5. faktör toplam varyansın \%4.8'lik kısmını açıklayan "Geliştirme, Yenileme" ve son olarakta 6. faktör toplam varyansın \%4.3'lük kısmını açıklayan "Çizgi" parametresi etkisi altında olduğu belirlenmiştir. Böylelikle peyzaj kalitesini belirlemek amacı ile kullanılan 25 adet parametre faktör analizi sonucunda 6 adet faktör ile peyzaj kalitesini belirleyecek olan varyansın toplamda \%59.6' sına karşılık gelmiştir. 
Tablo 5. Faktör analizi

\begin{tabular}{|c|c|c|c|c|c|c|c|}
\hline \multirow{2}{*}{ Parametreler } & \multicolumn{6}{|c|}{ Faktör Yükleri } & \multirow{2}{*}{ Ortak Varyans } \\
\hline & 1 & 2 & 3 & 4 & 5 & 6 & \\
\hline Güzel & 0.77 & 0.03 & 0.23 & -0.06 & -0.09 & -0.18 & 0.71 \\
\hline Özgün & 0.78 & 0.12 & 0.07 & -0.01 & 0.09 & 0.18 & 0.67 \\
\hline Etkileyici & 0.79 & 0.17 & 0.21 & -0.08 & -0.01 & 0.01 & 0.72 \\
\hline Rahatlatıcı & 0.57 & 0.33 & -0.18 & -0.18 & -0.05 & 0.10 & 0.52 \\
\hline Uyumlu & 0.59 & 0.30 & 0.22 & 0.14 & 0.00 & -0.03 & 0.52 \\
\hline Birlik & 0.67 & 0.26 & 0.37 & 0.02 & -0.11 & -0.01 & 0.67 \\
\hline Süreklilik & 0.54 & 0.21 & 0.38 & 0.21 & -0.27 & 0.08 & 0.61 \\
\hline Algılanabilir & 0.43 & 0.46 & 0.26 & -0.28 & -0.08 & 0.16 & 0.58 \\
\hline Güvenli & 0.33 & 0.70 & -0.13 & -0.00 & -0.02 & 0.05 & 0.62 \\
\hline Bakımlı & 0.27 & 0.67 & 0.16 & -0.09 & -0.13 & -0.14 & 0.57 \\
\hline Ulaşılabilir & 0.14 & 0.67 & 0.06 & -0.09 & -0.13 & -0.14 & 0.52 \\
\hline Hatırlanabilir & 0.13 & 0.73 & 0.25 & 0.02 & 0.11 & 0.11 & 0.64 \\
\hline Rekreatif & 0.06 & 0.70 & 0.28 & 0.04 & 0.00 & 0.08 & 0.59 \\
\hline Çeşitlilik & 0.15 & 0.43 & 0.23 & -0.22 & -0.26 & 0.01 & 0.38 \\
\hline Koruma & 0.18 & 0.35 & 0.47 & 0.02 & -0.21 & -0.29 & 0.51 \\
\hline Renk & 0.24 & 0.18 & 0.55 & -0.34 & 0.26 & 0.10 & 0.60 \\
\hline Form & 0.15 & 0.45 & 0.56 & 0.01 & 0.02 & 0.26 & 0.61 \\
\hline Doku & 0.42 & 0.12 & 0.70 & -0.15 & 0.03 & 0.01 & 0.71 \\
\hline Beğeni & 0.49 & 0.21 & 0.56 & 0.12 & -0.03 & -0.00 & 0.63 \\
\hline Karmaşıklık & -0.13 & -0.35 & -0.10 & 0.46 & 0.02 & -0.26 & 0.44 \\
\hline Doğal & -0.02 & -0.13 & 0.19 & 0.59 & 0.16 & 0.26 & 0.51 \\
\hline Tanıdık & 0.08 & 0.09 & -0.15 & 0.70 & -0.04 & -0.11 & 0.55 \\
\hline Geliştirme & -0.12 & 0.07 & 0.04 & 0.03 & 0.80 & 0.06 & 0.67 \\
\hline Yenileme & 0.07 & -0.19 & -0.00 & 0.05 & 0.61 & -0.45 & 0.63 \\
\hline Çizgi & 0.07 & 0.09 & 0.04 & -0.04 & -0.05 & 0.81 & 0.68 \\
\hline Varyans (\%) & 31.2 & 8.1 & 5.8 & 5.4 & 4.8 & 4.3 & 59.6 \\
\hline
\end{tabular}

\section{TARTIŞMA ve SONUÇ}

Akarsu kıyılarında gerçekleştirilen rehabilitasyon çalışmalarının kıyıların peyzaj kalitesi üzerindeki etkilerinin araştırıldığı bu çalışma, Trabzon Of ilçesi Solaklı akarsuyunda gerçekleştirilen "Solaklı Vadisi İyileştirme Projesi" kapsamında tamamlanan göletler ve park alanlarını konu almıştır. Alanın önceki ve sonraki durumu arasındaki önemli algı değişimlerini tanımlamıştır.

Akarsu kıyılarının insan ihtiyaçlarına bağlı olarak şekil değiştirdiği, başlangıçta yararlı fakat zamanla zararlı kullanımlara dönüştüğü görülmektedir. Günümüzde gelinen noktada yapılan yanlışlıkların farkındalığı ortaya çıkmış bu alanların daha önceki güzel yapılarına tekrar kazanabilmeleri için çeşitli rehabilitasyon ve yenileme projeleri gerçekleştirilmektedir. Yapılan rehabilitasyon çalışmaları ile bu kıyıların peyzaj kalitesinin artarak rekreasyonel olanaklar sunduğu ve kullanıcılar tarafından çok daha fazla tercih edildiği ortaya çıkmaktadır. Çalışma bu yönüyle Özgüner vd. (2012) ve Önen (2007) yaptıkları çalışmalarla benzer sonuçlar göstermektedir. Bununla birlikte akarsu kıyılarında gerçekleştirilen planlamaların koruma kullanma yapısının olup olmadığının ortaya konması ayrıca araştırılabilir.

Peyzaj tasarımlarının insanların görsel beğenisi üzerinde ne denli etkin olduğu ortaya konmuştur. Her ne kadar "doğal güzeldir" sloganı genel anlamda kabul görse de bu çalışma da elde edilen sonuçlarda bunun tam tersi görülmektedir. Öyleki yapılan anketler sonucunda alanın önceki durumunun daha doğal ve tanıdık olduğu ortaya çıkmış fakat bu durum beğenilmemiştir. Oysa Arriaza vd. (2004) ve Acar vd. (2006) yaptıkları çalışmalarda doğal alanların daha çok beğenildiği görünmektedir. Bunun nedeni çalışma alanının eski durumunun doğal olmasına rağmen karmaşık göründüğü, yenilenmesi ve geliştirilmesi gerektiğinin de benzer şekilde yüksek skorlar almasıyla ilişkilendirilebilir.

Alanın şimdiki durumunun ise uyumlu, algılanabilir, sürekli, daha bütün, çizgi ve form açısından daha etkili olduğu belirlenmiştir. Bu durumun alandaki yeşil dokunun su ve yapısal elemanlarla daha iyi organize edilmesi ve kıyı çizgisinin belirginleştirilmesinden kaynaklandığı düşünülmektedir (Özgeriş ve Karahan 2015). Ayrıca yeni 
durumun su, bitki örtüsü, arazi yapısı ve sahip olduğu mekânsal öğeler açısından çeşitlilik gösterdiği ve çeşitlilik ile peyzaj değeri arasında önemli bir ilişki olduğu Hunziker ve Kienast (1999) çalışmasında görülmektedir.

Alanın rekreatif imkanlar açısından daha çok tercih edildiği, hatırlanabilir olduğu ve beğenildiği ve bu parametrelerin bakımlıık ile direkt olarak bağlantılı olduğu görülmektedir. Benzer çalışmalarda bakım parametresinin peyzaj kalitesini etkilediği, bakımsız alanların bakımlı alanlara oranla daha aza tercih edildiği görülmektedir (Çakçı ve Çelem 2009; Aytaş ve Uzun 2015). Su varlığının ve su yüzeyinin artmasının da alanın tercih edilmesinde ve beğenilmesinde önemli etkenlerden biri olduğu göz ardı edilemez. Birçok çalışmada (Schroeder 1982; Arriaza vd. 2004; Özhancı ve Yılmaz 2011) su öğesinin peyzaj kalitesini estetik anlamda olumlu olarak arttırdığı belirtilmiştir.

Yapılan çalışma ile akarsu kıyılarında gerçekleştirilecek rehabilitasyon ve yenileme projelerinin kıyılara farklı işlevler kazandırarak kıyıların değerini arttırdığı, kıyıları bulunduğu alandaki yeşil dokuyla bütünleştirdiği, kıyı peyzajının kalitesinin arttığını ve kıyıya ulaşımı sağlayarak kullanım fırsatları yarattığı ortaya çıkmaktadır. Sonuç olarak yapısı bozulan akarsu kıyılarının planlanmasına bağlı olarak rekreasyonel olanaklar kazanmasıyla yeniden kimlik kazandığı, peyzaj kalitesinin ve değerinin arttığı ve dikkat çekici ve etkileyici görünümleriyle kullanıcılar için uygun alanlar olarak önem kazandıkları belirlenmiştir. Bu nedenlerle ilerde gerçekleştirilecek havza planlama çalışmalarında bu gibi rehabilitasyon çalışmalarına yer verilmeli ve doğal yapısı bozulmuş, değerini kaybeden alanlar yeniden peyzaja kazandırılarak halkın kullanımına sunulmalıdır.

\section{TEŞEKKÜR}

DSi Trabzon 22.Bölge Müdürlüğü'ne katkılarından dolayı teşekkür ederim.

\section{KAYNAKLAR}

Acar C (2001) Trabzon Yöresi Degirmendere ve Solaklı Havzaları Yol Sevlerinde Yetişen Yer Örtücü Bitkiler, Kafkas Üniversitesi Artvin Orman Fakültesi Dergisi, 1: 43-53
Acar C, Çiçek Kurdoğlu B, Kurdoğlu O, Acar H (2006) Public preferences for visual quality and management in the Kackar Mountains National Park (Turkey). International Journal of Sustainable Development and World Ecology 13 (6): 499-512

Acar C, Sakıcı Ç (2008) Assessing Landscape Perception of Urban Rocky Habitats, Building and Environment 43: 1153-1170

Acar C, Güneroğlu AN (2009) Trabzon kentindeki çizgisel bitki kompozisyonlarının tür çeşitliliği ile işlevsel ve görsel değerleri üzerine bir araştırma, Karadeniz Teknik Üniversitesi, Ekoloji dergisi, Trabzon, 18 (72): 65-73

Aksungur M, Alkan A, Zengin B (2007) Karadeniz alabalığının tatlısu ortamındaki göçü üzerine bazı çevresel parametrelerin etkisi, Ekoloji, 17 (65): 28-35

Arriaza M, Canas-Ortega JF, Canas-Madueno JA, Ruiz-Aviles P (2004) Assessing the visual quality of rural landscapes, Lanscape and Urban Planning 69 (1): 115-125

Aytaş I, Uzun S (2015) Düzce kent merkezindeki yaya alanlarının görsel peyzaj kalitesinin belirlenmesi, İstanbul Üniversitesi Orman Fakültesi Dergisi, 65 (1): 11-29.

Bulut Z, Yılmaz H (2008) Determination of landscape beauties through visual quality assessment method: a case study for Kemaliye (Erzincan/Turkey), Environ Monit Assess, 141: 121-129

Burmil S, Daniel TC, Hetherington JD (1999) Human values and perceptions of water in arid landscapes, Landscape and Urban Planning 44: 99-109

Clay GR, Smidt RK (2004) Assessing the validity and reliability of descriptor variables used in scenic highway analysis, Landscape and Urban Planning, 66 (4): 239-255

Çakcı I, Çelem H (2009) Kent parklarında görsel peyzaj algısının değerlendirilmesi, Tarım Bilimleri Dergisi 15(1): 88-95

Daniel TC (2001) Whither scenic beauty? Visual landscape quality assessment in The 21st Century, Landscape and Urban Planning, 54: 267-281

Dramstad WE, Tveit MS, Fjellstad WJ Fry GLA (2006) Relationships between visual landscape preferences and map-based Indicators of landscape structure, Landscape and Urban Planning, 78: 465474

Gülez S, Kaya LG, Dönmez Ş, Çetinkale S, Koçan N (2007) Muglada kıyı alanı peyzaj düzenlemesi üzerine bir çalışma, ZKÜ Orman Fakültesi Dergisi, 9: 12

Gültürk P, Şişman EE (2015) Tekirdağ kent merkezi kıyı şeridinin görsel peyzaj kalitesi yönünden değerlendirilmesi ve mekan tercihine etkisi, Adnan Menderes Üniversitesi Ziraat Fakültesi Dergisi, 12 (1): 81-89

Guneroglu A (2010) Marine litter transportation and composition in the coastal Southern Black Sea Region, Scientific Research and Essays, 5 (3): 296-303

Güneroğlu A, Dihkan M, Karsli F (2014) Dynamic management of the coasts: Marine spatial planning, Proceedings of The Institution of Civii Engineers-Maritime Engineering, 167: 144-153

Guneroglu A (2015) Coastal changes and land use alteration on Northeastern Part of Turkey, Ocean and Coastal Management 118(Part B): 225-233

Guneroglu N, Ozdemir U, Guneroglu A (2016) Decisions on quality assurance criteria of recreational beaches, Proceedıngs of The 
Instıtutıon of Civil Engineers-Municipal Engineer, doi.org/10.1680/jmuen.15.00023

Hunziker M, Kienast F (1999) Potential Impacts of changing agricultural activities on scenic beauty - a prototypical technique for automated rapid assessment, Landscape Ecology 14: 161-176

Kalın A (2004) Çevre tercih ve değerlendirmesinde görsel kalitenin belirlenmesi ve geliştirilmesi Trabzon sahil bandı örneği, Karadeniz Teknik Üniversitesi Fen Bilimleri Enstitüsü, Doktora Tezi, Trabzon

Kılıçaslan Ç (2006) İinci Konutların deniz kıyılarına etkisi, Süleyman Demirel Üniversitesi Orman Fakültesi Dergisi, Seri: A, 1: 147-156

Müderrisoğlu H, Eroğlu E (2006) Bazı ibreli ağaçların kar yükü altında görsel algılanmasındaki farklılıklar, Süleyman Demirel Üniversitesi Orman Fakültesi Dergisi, Seri: A, 1: 136-146

Özgeriş M, Karahan F (2015) Rekreasyonel tesislerde görsel kalite değerlendirmesi üzerine bir araştırma: Tortum ve Uzundere (Erzurum) Örneği, Artvin Çoruh Üniversitesi Orman Fakültesi Dergisi, 16 (1): 40-49

Özgüner H, Eraslan Ş, Yılmaz S (2012) Public perception of landscape restoration along a degraded urban streamside, Land Degradation and Development, 23: 24-33

Özhancı E, Yılmaz H (2011) Rekreasyon alanlarının görsel peyzaj kalitesi yönünden değerlendirilmesi; Erzurum Örneği, Iğdır Üniversitesi Fen Bilimleri Enstitüsü Dergisi, 1(2): 67-76
Sağlık A, Erduran F, Çelik A (2012) Kent içi akarsuların rekreasyonel yönden kullanımı: Çanakkale Sarıçay örneği, Biyoloji Bilimleri Araştırma Dergisi, 5 (1): 43-50

Schroeder HW (1982) Preferred features of urban parks and forests, Journal of Arboriculture 8 (12): 317-322

Terzioğlu S, Anşin R, Kılınç M, Acar C (2007) Vascular plant diversity in Solaklı watershed in Northeastern Turkey, Phytologia Balcanica, 13 (2): 213-222

URL_1http://www.ormansu.gov.tr/osb/haberduyuru/guncelhaber/12 $-05-$

08/Trabzon_Solakl\%C4\%B1_Vadisi\%E2\%80\%99ndeki_Muhte\%C5 \%9Fem_Rekreasyon_Projesinin_\%C4\%BOlk_Kademesi_Tamamlan d\%C4\%B1.aspx?sflang=tr, 03/03/2016

URL_2 http://www.ofhayrat.com/Resimlerim/solakli.html, 03/03/2016

Uzun B, Çelik N (2014) Sustainable management of coastal lands: A new approach for Turkish Coasts, Ocean \& Coastal Management, 95: 53-62.

Yamashita S (2002) Perception and Evaluation of water in landscape: use of photo-projective method to compare child and adult residents' perceptions of a Japanese River environment, Landscape and Urban Planning, 62: 3-17 